\title{
Ethical Challenges of Prenatal Diagnosis of Fetal Cardiac Anomaly in a Developing Country in Sub-Saharan Africa
}

\author{
Bosede Ehelamioke ADEBAYO ${ }^{\mathrm{a}}$, Janet Atinuke AKINMOLADUN ${ }^{\mathrm{b}}$
}

\section{INTRODUCTION}

Congenital heart defects constitute one of the most common groups of congenital anomalies seen in live births, with an incidence of 3-10/1000 live births (1). Prenatal diagnosis of congenital heart defects has been made in the last three decades using fetal echocardiography (2). Prenatal diagnosis of congenital anomalies presents ethical challenges ranging from counselling the parents to managing their decisions based on the diagnosis. The physician is faced with ensuring the mother's beneficence and autonomy and, in some circumstances, the fetus's autonomy (when viewed as a patient) (3). The ethical challenges are also multifaceted depending on the cultures and development of the countries $(4,5,6)$. These challenges include the option of termination and religion $(6,7)$, the possibility of available interventions $(6,8)$, and available legal framework (6). Nigeria, like some other developing countries, has a therapeutic gap associated with prenatal diagnosis. Therapeutic gap refers to the space that opens up between the repertoire of tests for genetic diseases and conditions on the one hand and the therapeutic options that are available to mitigate, combat, or eliminate these diseases on the other (9). This gap is likely to exist in countries aiming for growth in scientific and technological advances without accompanying cultural, economic, legal and political advancement (9). The causes of the gap may differ; for example, in Latin America, the gap was noted between the diagnosis of fetal anomalies and access to safe and legal abortion if desired (10). In contrast, in Australia, the therapeutic gap exists in making prenatal genetic diagnosis and having no treatment for the condition diagnosed, in this case, Huntington disease (11).

Therapeutic gaps contribute to the ethical challenges experienced with prenatal screening. In Nigeria, the legal framework is still strict on abortion, except the mother's life is in danger; choosing abortion for anomalies diagnosed during prenatal screening is illegal (12). However, it appears that many women in Nigeria are not aware of this limitation (13), as shown by Enabudoso and Akinmoladun. They found that more than $60 \%$ of the women studied would have opted to terminate a pregnancy with a prenatal diagnosis of severe congenital anomaly.

The diagnosis of congenital heart disease in the fetus has arguably improved the outcome of some children with a fetal diagnosis of congenital heart disease $(14,15,16)$. These factors have contributed to disparities in children with congenital heart diseases between developed and developing countries. For example, mortalities from congenital heart diseases were estimated globally to be 300,000, with more than $50 \%$ occurring in children < 1 year of age (17), with Asia and Africa accounting for almost half of these deaths. There is, therefore, a need for early diagnosis of congenital heart diseases in the prenatal period to mitigate the scourge of mortalities from congenital heart diseases. There is, however, a need to bridge the therapeutic gap for the effective prevention of mortalities.

Systematic scanning for the fetal anomaly is not widely available, unlike routine scans, as this requires specific training and expertise $(6,18)$. A few centres perform fetal echocardiography (12) in Nigeria, but data is sparse (12) on the findings and ethical dilemmas experienced, although this is changing. Prenatal diagnosis with ultrasound is gaining ground in Nigeria, with ethical challenges being documented (19). UCH (University

${ }^{a}$ Uzm. Dr., Department of Paediatrics, University of Ibadan, Nigeria $₫$ ehelamiokay@yahoo.co.uk

bepartment of Radiology, University of Ibadan, Nigeria

Gönderim Tarihi: $09.10 .2020 \bullet$ Kabul Tarihi: 19.03.2021 
College Hospital) Ibadan systematic anomaly fetal ultrasonography screening commenced five years ago with the fetal echocardiography component 2 years later. For example, the case of XX typifies some of the ethical challenges of prenatal diagnosis of congenital heart disease in Nigeria. The case described subsequently illustrates some of these challenges.

$\mathrm{XX}$ is the product of a 34-week gestation, delivered to a 35-year-old P3+0 (3 alive) mother. XX's mother received antenatal care from the 8th week of gestation. There was no history of exposure to any known teratogenic agent or radiation in the mother during the pregnancy. There is no history of fever or exanthematous rash in early pregnancy (note that there is no routine vaccination against rubella). A routine anomaly scan at 21 weeks GA revealed bilateral choroid plexus and hyperechoic bowel loops, based on which fetal echocardiogram was requested. Fetal echocardiogram at 23 weeks showed laevocardia with normal situs. The foramen ovale was patent with a right to left shunting of blood. Two pulmonary veins (one on each side) were identified by doppler draining into the left atrium. There was atrioventricular and ventriculoarterial concordance with the aorta exiting the LV and the PA, leaving the RV with normal crossing of the great vessels. There was no evidence of obstruction to flow through the great vessels. Both inlet valves were patent with an inlet VSD. The rhythm was regular, with a heart rate of $154 \mathrm{bpm}$. No other structural abnormality was identified. We counseled the mother on these findings and the possibility of a genetic syndrome. There are no resources for amniocentesis in our center for confirmation. (Amniocentesis for prenatal diagnosis is not widely available in Nigeria, and where available, the genetic aspect of the screening is not readily available and affordable). However, the mother requested for termination of the pregnancy and was not willing to pursue a diagnostic course. The option of termination was refused her, as the pregnancy termination was not legally possible in our center due to the existing abortion laws in the country (Nigeria). She had no option but to continue with the pregnancy.

The mother had an emergency cesarean section at 34 weeks gestational age on account of pre-eclampsia and three previous cesarean sections. The baby weighed $2 \mathrm{~kg}$ with Apgar scores of $7^{1}, 9^{5}$. She was admitted into the Special Care Baby Unit (this unit manages premature newborns who require intensive and non-intensive care) with respiratory distress features that resolved within 72 hours. She had dysmorphic features (broad forehead, low set ears, fixed flexion deformities of fingers). She was not pale, not cyanosed, and had no jaundice. She was dyspnoiec with a respiratory rate of 70 breaths per minute and had no added sounds. Pulses were of normal volume, regular and synchronous. The first and second heart sounds were normal with no murmur. No other abnormality was observed.

Echocardiography revealed Normal situs with an inlet VSD (Ventricular Septal defect) measuring $8 \mathrm{~mm}$. No pericardial effusion, no other structural anomaly, and she had good systolic function. She was subsequently discharged after one week. She was followed up in both the neonatal and cardiac clinics. A cardiac murmur was heard at six weeks, and she was commenced on oral diuretics until she had definitive surgery for a VSD.

XX was taken outside Nigeria for cardiac surgery and genetic diagnosis. Edward syndrome has since been confirmed. XX is severely lagging in attaining age-appropriate milestones.

Mother has had to be managed for depression for the first time after this delivery.

\section{DISCUSSION}

The detection of congenital anomalies in the fetus is supposed to be one significant benefit of anomaly scans. Others include early interventions by specifically selecting places of delivery with adequate preparedness, options of fetal intervention, psychological preparedness for the family, and the choice of termination after adequate counseling. Making a diagnosis of congenital anomalies is only as useful as the actions taken with the information obtained. Some studies have reported better outcomes for critical congenital heart diseases 
in developed countries with facilities for intervention, neonatal transportation, and funds for care, reducing morbidity and some mortality due to these congenital anomalies (20). In these climes, adequate support exists at every level; medical, social, spiritual, and psychological.

However, in a developing country like Nigeria, there are severe limitations concerning possible interventions and available support. In the case presented, first was the maternal desire to obtain a termination of the pregnancy when the diagnosis of a congenital anomaly was made. This reflects the poor knowledge of the populace on the restrictive abortion laws in Nigeria (13). This was not obtainable because abortion is not legalized in Nigeria except when the mother's life is at risk (21). This insufficient knowledge of abortion laws explains why a woman would consider termination when it is not legally available in the country under the given circumstances. The abortion laws do not characterize the risks to the mother's life, which may range from mental to medical risks.

For the physician, the burden of counseling the woman being aware of these limitations is also a dilemma. First, the counsel on the possible diagnosis of a chromosomal anomaly where amniocentesis for genetic abnormality is not readily available is incomplete. For example, performing amniocentesis is a skill that obstetricians in our center possess, but sample analysis is not available within the center, neither outside our center at affordable rates. The paucity of laboratory backup for genetic analysis is a known drawback in the practice of prenatal diagnosis in developing countries, as described by Wanapirak et al. (22). It is essential to understand that the diagnosis of a chromosomal abnormality could not be made at the time of these considerations. Added to this is the challenge of obtaining open heart surgery in Nigeria (23).

The inability of the mother to therefore obtain an abortion legally resulted in the delivery of the baby. Inability to access legitimate termination of the pregnancy further compounded the ethical challenges as the need to then care for the newborn and the responsibility of care rested on the parents in a society where healthcare is mainly borne out of the pocket (24). As the fetus has now become an individual, bioethics and maternal instincts demand that care be given. This culminated in parents sourcing for funds for definitive surgery outside Nigeria. It was also during this trip that a genetic diagnosis of Edward syndrome was made. Should surgery have been done? This is a difficult question to answer as the managing team outside Nigeria did not communicate with this article's writers. However, it is understandable that sought care was given as payment was made. As described, the mother has had challenges with her mental health. This is not unexpected, as the child has markedly delayed milestones making her care challenging. This indicates the need for psychological support in women who have had this diagnosis made. This is even of more relevance in Nigeria since there are limited options for a mother carrying a baby with congenital cardiac malformations. The repair of the VSD has prolonged the child's lifespan, although the quality of life may be debated. This is because the cardiac repair has reduced the frequency of hospital visits for the respiratory complications of the VSD and probably mortality secondary to the lesion.

This scenario is one that will recur, except some changes are made. There is a need to establish an effective program to provide needed support in definitive care and psychological support for mothers who have anomaly scans. A multidisciplinary team consisting of the obstetrician, radiologist, pediatric cardiologist, cardiothoracic surgeon, neonatologist, nurses, clinical psychologists, counselors, and religious leaders should be constituted in centers where these scans are done. There is a need to review the laws governing termination to give women a choice in the cases of severe anomalies indeed to reduce the burden on the mothers of such fetuses. The burden of fetuses with severe anomalies is not borne by the family of the affected baby alone but also by the health care system. It is for this reason that a review of the laws governing pregnancy terminations be reviewed to allow the woman more liberality and autonomy; not only this but there is a need to improve the infrastructure to provide definitive care for children with congenital heart defects. 
Consent was obtained for this write-up from the client.

\section{REFERENCES}

1. Rychik J, Ayres N, Cuneo B, Gotteiner N, Hornberger L, Spevak PJ, et al. American society of echocardiography guidelines and standards for performance of the fetal echocardiogram. Journal of the American Society of Echocardiography. 2004;17(7):803-10.

2. Donofrio MT, Moon-Grady AJ, Hornberger LK, Copel JA, Sklansky MS, Abuhamad A, et al. diagnosis and treatment of fetal cardiac disease: A scientific statement from the American heart association. Circulation. 2014;129(21):2183-242.

3. Chervenak FA, McCullough LB, Skupski D, Chasen ST. Ethical Issues in the Management of Pregnancies Complicated by Fetal Anomalies. Obstetrical \& Gynecological Survey [Internet]. 2003;58(7). Available from: https://journals.lww.com/obgynsurvey/Fulltext/2003/07000/Ethical_Issues_in_the_Management_of_ Pregnancies.23.aspx

4. Haidar H, Vanstone M, Laberge A-M, Bibeau G, Ghulmiyyah L, Ravitsky V. Implementation challenges for an ethical introduction of noninvasive prenatal testing: a qualitative study of healthcare professionals' views from Lebanon and Quebec. BMC Medical Ethics [Internet]. 2020;21(1):15. Available from: https://doi.org/10.1186/ s12910-020-0455-x

5. Hewison J, Green JM, Ahmed S, Cuckle HS, Hirst J, Hucknall C, et al. Attitudes to prenatal testing and termination of pregnancy for fetal abnormality: a comparison of white and Pakistani women in the UK. Prenatal Diagnosis: Published in Affiliation With the International Society for Prenatal Diagnosis. 2007;27(5):419-30.

6. Chima S, Mamdoo F. Ethical and legal dilemmas around termination of pregnancy for severe fetal anomalies: A review of two African neonates presenting with ventriculomegaly and holoprosencephaly. Nigerian Journal of Clinical Practice. https://www.njcponline.com/article. asp?issn=113077;year=2015; volume=18;issue=7; ;page=31; epage=39; aulast=Chima;t=5):31 OP-39 VO -18 .

7. Zubani A. Congenital Heart Disease: Genetic Aspect and Prenatal and Postnatal Counseling. In: Asra I, editor. Rijeka: IntechOpen; 2018. p. Ch. 20. Available from: https://doi.org/10.5772/intechopen.72486

8. Chetty S, Garabedian MJ, Norton ME. Uptake of noninvasive prenatal testing (NIPT) in women following positive aneuploidy screening. Prenatal Diagnosis. 2013;33(6):542-6.

9. Simpson B. Negotiating the Therapeutic Gap: Prenatal Diagnostics and Termination of Pregnancy in Sri Lanka. Journal of Bioethical Inquiry [Internet]. 2007;4(3):207-15. Available from: https://doi.org/10.1007/s11673-0079070-5

10. Ballantyne A, Newson A, Luna F, Ashcroft R. Prenatal Diagnosis and Abortion for Congenital Abnormalities: Is It Ethical to Provide One Without the Other? The American Journal of Bioethics [Internet]. 2009 Aug 3;9(8):48-56. Available from: http://dx.doi.org/10.1080/15265160902984996

11. Taylor SD. Predictive Genetic Test Decisions for Huntington's Disease: Elucidating the Test/No-test Dichotomy. Journal of Health Psychology [Internet]. 2005 Jul 1;10(4):597-612. Available from: https://doi. org/10.1177/1359105305053442

12. Enabudoso E, Ikubor J. The Challenges of Diagnosis and Management of Fetal Anomalies in Low Resource settings. African Journal of Tropical Medicine and Biomedical Research. 2013;2(1):7-12.

13. Enabudoso E, Akinmoladun J. The attitude of Nigerian women to termination of pregnancies with major congenital anomalies. Annals of Health Research. 2020;6(3):325-32.

14. Vaidyanathan B, Kumar S, Sudhakar A, Kumar RK. Conotruncal anomalies in the fetus: Referral patterns and pregnancy outcomes in a dedicated fetal cardiology unit in South India. Annals of pediatric cardiology [Internet]. 2013 Jan;6(1):15-20. Available from: https://pubmed.ncbi.nlm.nih.gov/23626429

15. Kulkarni S. Does fetal echo help the fetus? Annals of pediatric cardiology [Internet]. 2013 Jan;6(1):21-3. Available from: https://pubmed.ncbi.nlm.nih.gov/23626430

16. Zimmerman MS, Smith AGC, Sable CA, Echko MM, Wilner LB, Olsen HE, et al. Global, regional, and national burden of congenital heart disease, 1990-2017: a systematic analysis for the Global Burden of Disease Study 2017. The Lancet Child and Adolescent Health. 2020;4(3):185-200. 
17. Osinusi BO, Marinho AO. The variation of fetal bi-parietal diameter with gestational age in Ibadan, Nigeria. Trop J Obstet Gynecol. 1987;8:19-21.

18. Adebayo BE, Agaja OT. Awareness of fetal echocardiography and its indications among paediatricians in Nigeria. Prime Medics Journal. 2019;2(1):19-26.

19. Holland BJ, Myers JA, Woods CR. Prenatal diagnosis of critical congenital heart disease reduces risk of death from cardiovascular compromise prior to planned neonatal cardiac surgery: A meta-analysis. Ultrasound in Obstetrics and Gynecology. 2015;45(6):631-8.

20. United Nations. Abortion Policies and Reproductive Health around the World [Internet]. Economic \& Social Affairs. 2014. 1-49. Available from: http://www.un.org/en/development/desa/population/publications/pdf/ policy/AbortionPoliciesReproductiveHealth.pdf

21. Kaasen A, Helbig A, Malt UF, Næs T, Skari H, Haugen G. Maternal psychological responses during pregnancy after ultrasonographic detection of structural fetal anomalies: A prospective longitudinal observational study. PLoS ONE. 2017;12(3).

22. Wanapirak C, Buddhawongsa P, Himakalasa W, Sarnwong A, Tongsong T. Fetal Down syndrome screening models for developing countries; Part II: Cost-benefit analysis. BMC Health Services Research [Internet]. 2019;19(1):898. Available from: https://doi.org/10.1186/s12913-019-4699-4

23. Bode-Thomas F. Challenges in the Management of Congenital Heart Disease in Developing Countries. In: Rao SP, editor. Congenital heart diseases- Selected aspects. 2012.

24. Aregbeshola BS. Out-of-pocket payments in Nigeria. Lancet (London, England) [Internet]. 2016 Jun 18 [cited 2021 Feb 3];387(10037):2506. Available from: http://www.ncbi.nlm.nih.gov/pubmed/27353683 